\title{
Education for Rural Transformation in Thailand: Perspectives on Policies and Practices
}

\author{
Harbans Singh Bhola* \\ Indiana University, Indiana, USA
}

\begin{abstract}
To engage meaningfully on the subject of "Education for Rural Transformation," it is essential first to understand the concept of the "Rural Condition" as well as of "Education" -- which is influenced by social, economic, political, technological and cultural factors. There are two additional complexities in that the "Rural Condition" itself is not something stable and absolute but is indeed in perpetual flux across Time and Place; and that the rural condition is inconceivable without at the same time understanding the "Urban Condition."

Concomitantly, "Education" itself will have to undergo transformation to serve as the lever of rural and urban transformations. Rural and urban transformations today have come to acquire one globally-focused mission, dealing with three objectives: mitigation of global warming, pursuing sustainable development and committing to poverty alleviation, in both rural and urban habitations.

For "Planned Action" informed by the general conceptual framework constructed here, the general must be contextualized in each particular setting of time, space and locality - responding to a specific "Political Economy"; to policy processes such as formulation, planning, mobilization, implementation and evaluation; and configurations of agents and adopters of planned actions. Finally, the "Logic of Action" must come from the dialectics between the structural and the instructional.
\end{abstract}

Keywords: Education for Rural Transformation, Rural Condition, Education, Sustainable Development

\section{Introduction and Context}

History of the Past enables our understandings of the Present; and our capacities to imagine and innovate the Future that we desire. Theory is - a set of principles tested in social (and/or laboratory) settings that are generalizable to multiple other settings. To put it in another way, "Theory is Commonsense changed into Un-common sense" which 
Education for Rural Transformation in Thailand 55

over time comes to qualify as General Knowledge usable in social settings from the Local to the Global. Application of General Knowledge to a specific Location would require Contextualization - an exercise of assigning appropriate Meanings to social processes in a particular social setting, based on surrounding influences, circumstances and environments of that bounded location. Going from the Global to the Local is seldom one big leap but is mediated by several intermediate layers of formal and non-formal structures with special agendas.

\section{Common Conversations Versus Uncommon Conversations}

In parallel to Common Sense versus $U n$-common sense, we can talk of Common Conversations versus Uncommon Conversations. Conversation between and among individuals using language, to create shared meanings - is indeed the seed that sprouts into communities, then cultures, and then civilizations. In our times, we have come to develop Uncommon Conversations which take place in different Settings, using different Modes and Methods, among them: National and International Workshops, Seminars, Symposia and Conferences with for face-to-face interactions in a locality or teleconferences with participants from around the globe. It should be noted that the present International Symposium that has brought us together in Bangkok, Thailand, during 18th20th November 2013, was clearly one of those events of Un-common Conversations. It is worth mentioning that within Western nations of Europe, a respectable tradition of theory, research and writing for such conversational events has come to be developed as evidenced in the book "Educational Policy Borrowing and Policy Lending" (Phillips \& Ochs, 2004).

\section{Language of Our Discourse and Common Conversations}

Theory of Knowledge (i.e. Epistemology) informs us that Reality is not something lying out there to be seen and understood in the same one way, universally. Indeed, different Individuals and the Communities will construct their own meanings. The Language of Discourse we use in our Conversations on "Education for Rural Transformation" will carry different meanings in individual minds and Communities.

First, to distinguish between Transformation and mere Change may be problematic. Dictionary defines change as an alteration or substitution of one working system to another; and equates Transformation with complete "Metamorphosis" resulting in changed form, character and conditions; changing the very nature of a system regarding its ends, its means, and its values. In common conversations among common people, no such distinctions may be made.

Second, assigning meanings to the concepts of Rural and Urban is also problematic. Generally speaking, Rural refers to Countryside while Urban refers to cities and towns. To make the distinction more concrete, policy makers and planners use indicators of Population Size and Density; and relative contributions to the Economy by Agriculture and 
Forestry versus Industry and Services. Such distinctions seem to have become untenable as city dwellers practice "Urban-Agriculture," and city mayors may plant trees along roads and streets and build small parks inside cities; most importantly, the Radio and Television, and now the Cell phone, and the Internet that are spread all over the place. In this sense, old boundaries between the "Rural" and the "Urban" have disappeared (Bhola, 2011). There is persistent talk of the Yin-Yang of the Rural and Urban suggesting that nothing happens to the Rural without affecting the Urban and vice versa.

\section{A Case Study of Thailand}

With the above introduction and context in mind, we construct a case study on Thailand.

\section{Thailand's Immediate Past and Imminent Future: As in Gunner Myrdal's Rear-View Mirror 1968}

In written prose, it is possible to talk of Immediate Past and the Imminent Future and of the Present in-between, in sequences. In the existential world, however, contemporariness and concomitance prevails. Many different things happen at the same one time in complex, dialectical relationships - among and between the March of National History; Processes of Globalization, and Cycle of National Development Policies, their Implementation and Evaluations [See the Tabulation below].

Table 1

History, Development, and Globalization in Parallel Perspectives

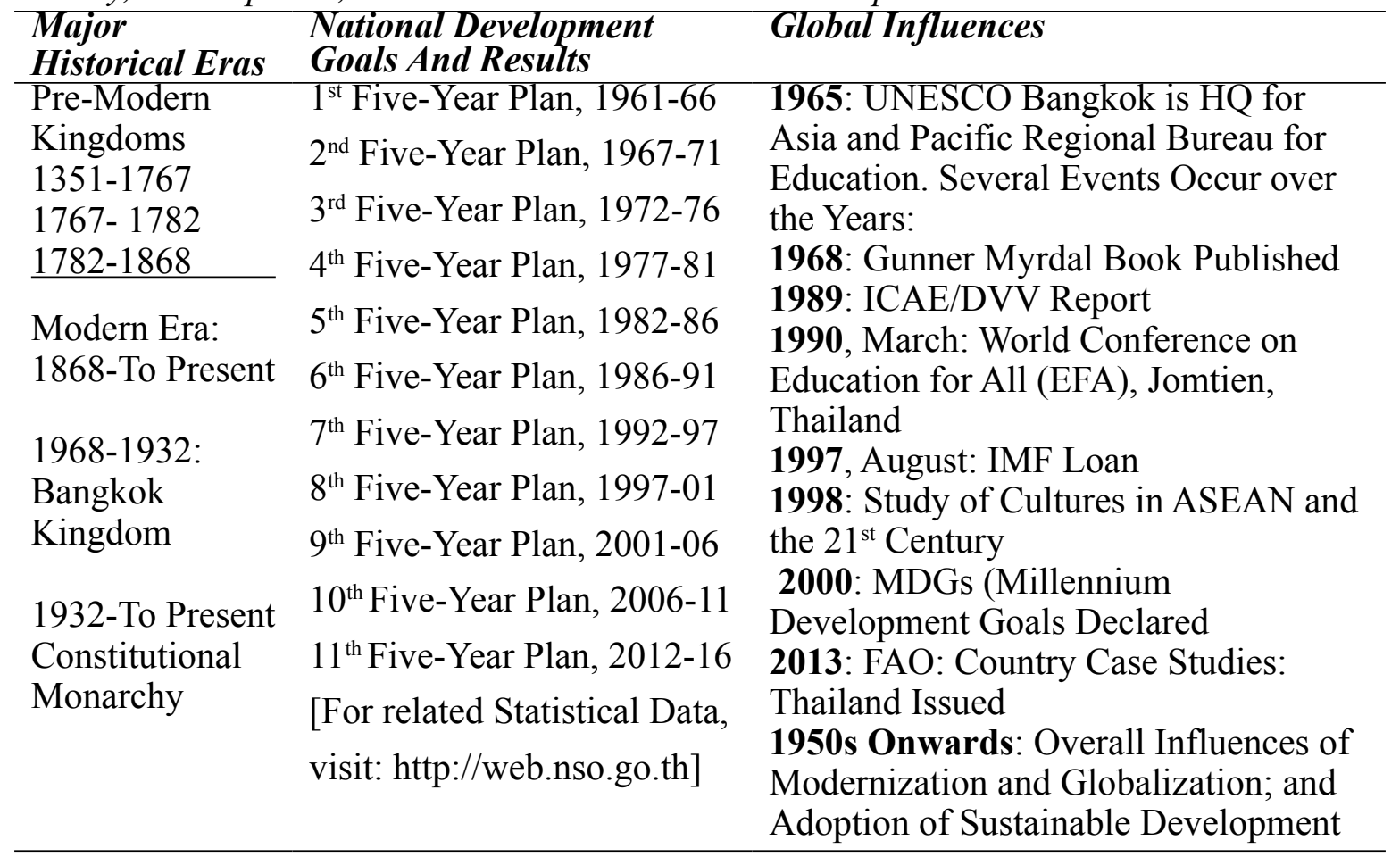


Education for Rural Transformation in Thailand 57

\section{A Thumb-nail Sketch of the History of Thailand}

Gunnar Myrdal begins by pointing to the unique History of Thailand for being the only country among its neighbors that did not inherit a colonial past. During the Second World War, when colonizers and despots did make unwelcome forced entries, Thailand was able to make shrewd and opportunistic alliances first with the Japanese and then with the Americans and the British. Consequently, no colonial language was forced upon the country and the impact of Western cultures on Thailand's political institutions remained relatively weak - that with mixed consequences. By mid-1960s, however, the dynamics had changed and there was a rapid increase of a Western-educated class of intellectuals, with contacts around the world through universities and through international institutions. Along with it came the tradition of permitting the elite the freedom of expression that was exceptional in the region (Myrdal, 1968, pp. 390-95).

Political economy in those times. When Myrdal wrote, there was little real planning in Thailand and almost no political debate on economic and social goals. "A vast spoils system" did seem to operate. Brief notations on the Agricultural Scene, the Industrial Scene and the Trade Sector and the State Sector can be made as follows:

Agricultural scene. As seen by Myrdal, the political system was such that power games were played "above the heads of the masses" thus enabling them to live peaceful lives uncomplicated by politics in the far away villages and in the poor quarters of the cities. A large proportion of the people were farmers with their own land and average levels of living were comparatively good by Asian standards. There were little signs of abysmal poverty (Myrdal, 1968, pp. 390-95).

Industrial scene. Industrial scene was almost entirely confined to processing raw materials, producing a few consumer goods like furniture, jewelry, playing cards, and toys. Manufacturing of building materials such as cement, bricks, and timber was another industry. There was no important heavy industry apart from a small steel mill.

Trade sector. Chinese residents in Thailand generally dominated trades and professions, except for employment in government, and in rice-farming.

State sector. Historical realities led to the state undertaking such activities as building and maintenance of irrigation systems, construction of railways, electricity production and water supply. The state had also entered the sugar, distilling, and tobacco businesses.

Development ideology as emerging in the 1960s. The Modernization Ideals as embedded in the Thai Development Ideology had a conservative slant. Extreme formulations of the egalitarian ideals were seldom expressed; greater equality, however, was often a part of the statement of policy goals (Myrdal, 1968, pp. 54, 59). Stated in another way, development goals were to raise standards of living by means of greater agricultural, industrial and power production. 


\section{Special Role of Education: Literacy as Key to Development}

Myrdal rightly paid special attention to history of Education in Thailand and to the key role of Literacy in the country's Development. According to his data, Literacy Rates in Thailand in the year 1947 were 69\% for Males and 36\% for Females; and by 1960 the Percentages had risen to $79 \%$ for Males and $56 \%$ for Females. This trend had continued into the late 1960s. Myrdal points out that part of the credit for high literacy rates in Thailand must be given to Adult Education; not all Literacy was acquired in Primary schools (Myrdal, 1968, p. 1972). He points out that Thailand had made government schools free up to the upper secondary level while at the tertiary level fees were charged even in public institutions. Moreover, dropout rates were surprisingly high throughout the system.

Myrdal does point to Thailand's Dilemma, as in most other developing countries, of having to face the clash between the nation's Local/Regional language versus a foreign language (such as English or French). Use of Local language at the primary levels works out well enough, though even here, the new knowledge in health and agriculture using "strange new concepts and words" (so-called scientific language) does not lend easy to local languages. At the Secondary Education level, curriculum development and delivery pulled teachers in different directions, not knowing which way to go. At the same time, a body of substantive knowledge for the Secondary level that must be taught offered dilemmas. Curriculum that would prepare learners for the Tertiary Level had to be delivered mostly in a Foreign Language. Quite a problem there!

Opening up to Western education. Even as the "education for the people" within the country was nothing to boast about, a particular social class of people in Thailand, had begun to understand the value of Western education and were going abroad - mostly to USA and UK -- to pursue higher education. Even as early as 1962-63, Thailand had 2,122 students studying abroad. In comparison, during the same year, figures for India were 10,869; for Philippines 2,524; Indonesia 2556; Pakistan 2246; Ceylon 397; and Burma (now Myanmar) 280. Fields of specialization were widespread and included Humanities, Education, Social Sciences, Natural Sciences, Agricultural Sciences, as well as Law, Engineering, Medicine. The pursuit of Education in Western countries never declined and had important consequences for both the institutionalization of the processes of educational planning and the objectives of education for the nation at all levels and in all locations.

\section{Future History Unfolds in the Context of Globalization}

Thailand like all other nations of the world had become a resident of the Global Village (McLuhan \& Powers, 1992). It had indeed been absorbing all of the general worldviews and global cultural mores for decades, continuously including Western tastes and products of daily use. Indeed, it was in response to Globalization that Thailand came to assume 
the idea of planned "Development" per se; and institutionalized the process in the form of NESDBO (National Economic and Social Development Board: Thailand's State economic planning agency).

Thailand now continues to resonate to the ever evolving conceptions of Development -- going from Development as Growth to join Economic Development with Social Development; and then with Human Resource Development. The new Development Ideology includes Justice for All based on equality by gender, and race, caste and creed. Development also has come to encompass dimensions of the Moral, the Educational and the Technological. Finally, Nations of the World have come to pursue Sustainable Development dedicated to development actions that would not despoil Human Environment in the near or distant future; within its own national boundaries or anywhere else around the Globe. All this did of course involve adoption of the ideology of Modernization - joined with Ideals of Moderation across the Global Village.

\section{United Nations as a Mediator of Globalization}

Education for All (EFA) conference, 1990. One of the most important events of United Nations as Mediator of Global Influences came to be staged in Thailand when it had the privilege of hosting the World Conference on Education for All: Meeting Basic Needs, organized jointly by an Interagency Commission (WCEFA) consisting of UNICEF, UNESCO and the World Bank, during 5-9 March 1990 in Jomtien, Thailand (Inter-agency Commission, 1990). The World Conference on Education for All (EFA) of 5-9 March 1990 in Jomtien, Thailand was truly a World Conference. Participants from 155 countries had come and had pledged to take the necessary steps to provide Primary Education for all children; and to massively Reduce Adult Illiteracy (Inter-agency Commission 1990). By any measure it was one of the most important events in the history of World Education. Later, the World Education Forum meeting in Dakar, Senegal during April 26-28, 2000, while re-affirming the commitments made in Thailand a decade ago, now offered a clearer statement of the goals to promote Education for All (EFA) (UNESCO, 2000).

The EFA Goals as now stated are:

Goal 1: Expand and improve comprehensive early childhood care and education, especially for the most vulnerable and disadvantaged children.

Goal 2: Ensure that by 2015 all children, particularly girls, children in difficult circumstances, and those belonging to ethnic minorities, have access to and are able to complete education that is free, compulsory and of good quality.

Goal 3: Ensuring that the learning needs of all young people and adults are met through equitable access to appropriate learning and life-skills programmes. 
Goal 4: Achieving a 50 per cent improvement in levels of adult literacy by 2015 , especially for women, and equitable access to basic and continuing education for adults.

Goal 5: Eliminating gender disparities in primary and secondary education by 2005, and achieving gender equality in education by 2015 , with a focus on ensuring girls' full and equal access to and achievement in basic education of good quality.

Goal 6: Improving all aspects of the quality of education and ensuring excellence of all, so that recognized and measurable learning outcomes are achieved by all, especially in literacy, numeracy and essential life skills.

The second even more momentous event promoted by the UN with a much more ambitious Agenda for citizens of the Golobal Village was the proclamation of the $U N$ Millennium Development Goals as summarized below:

UN Millennium Development Goals (2000 to 2015). Millennium Development Goals (MDGs) as declared by the UN in 2000 had the overall objective of "Tackling World Poverty" through eradicating extreme poverty and hunger; with crucial components including: Universal primary education; Gender equity and empowerment of women; Fighting child mortality; Improving maternal health; Combating HIV/AIDS, malaria and other diseases; Environmental sustainability; and Global partnership for development. A rather significant feature of the MDGs has been that the Stated Goals have been linked with clear and concrete targets to be achieved, which, in turn, could be evaluated using appropriate quantitative and/or qualitative measures (United Nations, 2008; See Abuom, 2010 for full details.). The UN Millennium Development Goals (1990-2015) are presented below:

Goal 1: Eradicate extreme poverty and hunger

Goal 2: Achieve universal primary education

Goal 3: Promote gender equity / Empower women

Goal 4: Fight child mortality

Goal 5: Improve maternal health

Goal 6: Combat HIV/AIDS, Malaria and other diseases

Goal 7: Environmental sustainability

Goal 8: Global partnership for development

It should be noted that two of the eight goals as stated in the MDG above are about education: Early Childhood Care and Education; and Adult Literacy - though, the emphasis is Literacy among Youth and Adults between 15 to 24 year old. Relating all education to learning of Life Skills is significant as well (Abuom, 2010).

High-Level-Panel (HLP) of Eminent Persons: Advice and support for achievement of MDG. Unfortunately, the expectations from MDG (2000-2010) have remained unfulfilled both in terms of coverage and schedules. Various extensions of time schedules 
Education for Rural Transformation in Thailand 61

have not produced results. A High-Level-Panel (HLP) of Eminent Persons constituted from political leaders at the Highest level of Governance, from some 25 countries from around the Globe is supposed to supervise the progress of MDG and to keep the UN Director General informed.

As conceived by the High-Level-Panel, MDG is now expected to achieve the following Goals by 2030: eradicating extreme poverty and hunger; and adopting and implementing development that will be environmentally sustainable. Most significantly, the HLP now insists on two different separate agendas: one for Millennium Development Goals (MDG); and another for Sustainable Development Goals (SDG). They also advocate strongly that the new agendas should be global in vision and be concerned not just with developing countries but indeed also with the developed world. While paying attention to eradication of hunger, HLP would also work towards sustainable patterns of consumption in highly developed countries. Both Governments and non-governmental organizations (NGOs) would be harnessed for the task.

\section{Assertions of Identity: Unswayed by Globalization}

(I) Old cultural roots with new branches: The "sufficiency" economy. Both of the Global Initiatives of Education for All (EFA); and the Millennium Development Goals (MDGs) came to be colored in the national philosophy of Sufficiency Economy bestowed by His Majesty King Bhumibol Adulyadej on the people of Thailand which has now come to be firmly rooted in Thai polity and society. Sufficiency Economy values "growth with economic stability over rapid but unbridled growth," thereby emphasizing Sustainable Development. In turn, Sufficiency Economy stresses the importance of Self-immunity "the need for communities to possess resilience against external or internal shocks; be those economic downturns, soaring fuel prices, natural disasters, and ill-health in families or bad harvests from the farms." At the national level, Sufficiency Economy and Self-immunity value building "macro-economic resilience to cope with the vagaries of the global economy and negative effects of globalization" - with Future Vision for Thailand that would be "Green, Happy and in Peace" (Government of Thailand, 2007).

(I-A) From the Moral to the Material. Being Moral is exemplary but not sufficient for the tasks of nation-building. To transform the "Material" world of everyday life of common peoples, would mean undertaking Planned Action on the Ground, involving a dialectic between the Structural and the Instructional-Informational, of all the Structures of the State, at the all levels from the Central to the Local. The Structural would deal with creating and /or re-creating networks of "Organizational and Institutional Structures; and the Instructional will have to be focused on human resource development to serve policy-makers and administrators on the one hand and on the other hand, prepare future beneficiaries of economic and social development in localities to benefit from new initiatives. 


\section{Structural-Instructional Dialectic in the Context of Thailand}

Impressive work has been done both in institution-building and in the area of education at the service of Sustainable Development. New Institutions and Organizations have indeed sprung up both in Rural and Urban areas. There is a commitment on the part of the State to achieve universal Primary Education for all children in the country, for boys and girls. Along with Primary Education, Thailand is also laying emphasis on Adult Education for all Adults and Young Adult -- bypassed or underserved, by the existing systems of Primary Education. There is huge expansion and quality improvement of Secondary Education; and University Education by opening more Colleges and Universities. Advanced degrees are also available in Agriculture - Kasetsart University in Bangkok is one example. Of greater significance is the greater exposure to Foreign Universities and Research Institutions by the constantly increasing middle class elite in towns (Thumboo, 1998).

\section{Need of Rudimentary “Science-Literacy” for Dialogic Actions: On Farms, in City Slums, in Clinics and Courts}

Thai as a language is more close to the languages of the East. Indeed, over half of the words in Thai are borrowed from Pali, Sanskrit, and old Khmer, with influence also of "Middle Chinese." Notwithstanding this rich linguistic heritage, Thai does not match with the richness of vocabularies of languages of the West, today's purveyors of Modernization. No wonder that modern realities of Business and Politics in Thailand have led to English serving as the "secondary language in the society" - though mostly by the Thai elite. Some Tinglish is taking shape slowly! There is "Hallo" for "Hello"; and "Cheque Bin" is heard in restaurants when the guests want to pay the Bill. But neither Thai nor Tinglish can take Extension Workers in Agriculture, Healthcare, in Clinics and Courts very far, in the fulfillment of today's communication needs. Farming has become more and more scientific - requiring knowledge of Chemistry to make intelligent choices of seeds and to use fertilizers. As more and more Childcare and Healthcare services in general are expanded, village level providers must be able to communicate suitable meanings of new concepts and processes in human Biology and Physiology. On the other hand, the Beneficiaries of all these offers from Extension Workers must also be able to understand at some level what is being offered and how they should respond. HIV-AIDS has become a serious enough problem in urban slums of Thailand. Those at the risk of HIV-AIDS or already suffering from it need to understand the special language of what must be done and why. Cases in small courts involving fraud or sexual assault also require understanding of the new vocabulary that may not be available in mother tongue languages of Thailand.

In addition to "Science-Literacy" as discussed above, there has been another progressive turn: a paradigm shift to Adult Education, and then on to Lifelong Education to Lifelong Learning." Education-for-Development enthusiasts in Thailand have also adopted the relatively new and highly progressive concept of Lifelong Learning which means that 
need for learning never ends, as demonstrated by the reanues or viovalızaluon and the needs for Knowledge-based production on farm and in factory, for maintenance of Health, for intelligent choices in Education and Leisure (Singh, 2002).

(II) Focus on agriculture. Rural and Agricultural are, more or less, synonymous terms - in Thailand, however, this statement needs qualification. In Thailand even long-time urbanites, define their individual identities from being migrants from particular villages; and Industries are making forays into the Rural by opening industrial plants in rural areas both for reasons of easy acquisition of land parcels and availability of relatively cheaper labor force.

\section{FAO Looks at Decades of Agriculture Development in Thailand}

A recent report prepared by Food and Agricultural Organization included six case studies on Thailand on topics as varied as: (1) Impact of decentralization on local level rural development in Thailand, by Ms Montip Krachangvej (2) Thailand cooperatives role in decentralized rural development for poverty alleviation and food security at the community level, by Asanee Ratanamalai, $\mathrm{PhD}$; (3) An alternative approach to development: A case study of the Bangchak petrol stations in Thailand by Dr. Supriya Kuandachakupt; (4) Decentralized rural development and the role of self help organizations in Nang Rong, Buriram, Wilas Lohitkul, Thailand; (5) Roles of agricultural cooperatives and village credit unions in rural financial markets in Thailand, by Paradorn Preedasak and Viroj NaRanong; and (6) Decentralized rural development and the role of self help organizations, Mrs Wannee Ratanawaraha, Thailand (FAO, 2013).

It is not possible within the scope of this paper to deal with all of six studies in detail, but the first of the six studies, dealing with "Impact of decentralization on local level rural development in Thailand," by Ms Montip Krachangvej," deserves a mention. Taking an administrative-managerial perspective, the study shows how relationships of government agencies at the top, and private businesses; and non-government organizations below, are mediated through village cooperatives.

\section{Social Protection of Peoples: Building Assets Through Micro-lending in Thailand}

People with low incomes whether they live in rural areas or urban or semi-urban areas, more often than not, need "Help to Help Themselves."

Thailand's "Village and Urban Revolving Fund" is one important initiative in that direction. The idea of Grameen Bank (Bank for Villages), first created by Prof. Muhhamad Yunus in Bangladesh as early as in 1976, had spread all around the world - Brazil has created "Bolsa Familia" that makes micro-credits or cash transfers to families in poverty, on the condition that parents use the micro-credits for sending their children to schools; or would have them vaccinated against typical childhood diseases. An estimated 120,000 microfinance initiatives are in place in countries around the world. 
In Thailand today, the "Village and Urban Revolving Fund" may be lending more money to more people than any other micro-lending project in the world. In 2011, the scheme had a total outstanding loan portfolio of $\$ 4.9$ billion with active borrowers that year standing at $8.5 \mathrm{~m}$. There are plans to inject $\$ 2.6$ billion in additional capital into the present network of nearly 80,000 village banks (Kaboski \& Townsend, 2005).

\section{Consideration of Education and Development in Thailand: Some Views From Inside}

A Group of Four Professionals holding important positions in the education and developments sectors of the state had some interesting views to share on "Education for Social Transformation" in Thailand, as participants in the International Symposium (ERT-4) organized jointly by the Institute of International Education (IIE), Stockholm University, Sweden; and the Faculty of Education and Psychology, the M.S. University of Baroda, India, during 2012:

Sudarat Sarnswang chose to deal with the over-arching Moral Principle embodied in the "Sufficiency Economy", a most significant contribution to the Development debate from Thailand, asking for raising standards of living together with raising moral standard (Sarnswang, 2012). Second participant, Surachai Jewcharoensakul took up the important question of "Policy into Practice" processes, citing a successful case of "From Farm to Fork" experience in putting education to work in promotion of rural development in particular locations in the country (Jewcharoensakul, 2012). Buasuwan discussed the important question of Human Resources Development and the significant role of Higher Education in preparing Professionals to guide and undertake all the tasks relating to effective "Policy-making - Program Development - Mobilization - Implementation - Evaluation." A case study of the Kasetsart University, an important Agricultural University of Thailand, was used as an exemplar case (Buasuwan, 2012). Finally, Mathinee Wongwanich Rumpagaporn invited attention to the newest tools of instructional technology, offering a narrative on the experiences of implementing the integration of Information and Communication Technology (ICT) in teaching-learning processes of small-sized schools in Thailand engaged in the larger process of Rural Transformation (Rumpagaporn, 2012).

(III) Advances in industrial and trade sectors. Modernization, or change in Westernstyle demands that Development be planned and pursued in both the dimensions of the Agricultural and the Industrial. Of course, this is true of Thailand as well. As reviewed in the receding, Thailand has done remarkably well in the agricultural sector. Happily, in the industrial and trade sectors as well, its performance has been equally impressive, if not more so.

One example: Thailand building dams abroad. An indication of how far Thailand has advanced in its engineering and industrial capacities in the ASEAN region is the contract a Thai construction company had won for building of the Xayaburi dam, the 
first on the lower Mekong River. Ch. Karnchang, a Thai construction company will be financed by Thailand's four largest banks to the tune of $\$ 3.5$ billion. The design of the dam incorporates modern "Fish passage technologies" to allow fish to migrate up and downstream and thereby keeping migration channels of fish intact, and the fishing resources of the river unhurt (The Economist, 2013, September 7).

\section{Thailand on the Global Stage: Embracing the ASIAN Nations of ASEAN}

Thailand is indeed a special drummer on the ASIAN/ASEAN stage. As early as 1961 UNESCO came to Thailand to establish UNESCO-Bangkok, the Asia Regional Office for Primary and Compulsory Education. In 1987, UNESCO-Bangkok was renamed as the Principal Regional Office for Asia and Pacific (PROAP), which focused on education, culture, communication, and social and human science. Since 2002 UNESCO- Bangkok has operated as the Asia and Pacific Regional Bureau for Education, responsible for 46 Member States and as cluster office representing the Organization in Thailand, Lao PDR, Myanmar, and Singapore

Over the years, UNESCO-Bangkok has attracted UNESCO and other International Agencies to come to Thailand to hold international events. Easily the most memorable was the World Conference on Education for All: Meeting Basic Needs, held jointly by Interagency Commission, WCEFA (Word Bank, UNESCO, UNICEF, \& World Bank) during 5-9 March 1990 in Jomtien, Thailand. A quarter of a century later, EFA still resonates in the proceedings of educational policy committees and commissions around the globe.

\section{Thailand and Asia-Pacific Economic Cooperation (APEC)}

Since its inception in 1989, the Asia-Pacific Economic Cooperation (APEC), a multilateral economic forum with 21 Members, has been uniquely successful in promoting regional economic growth through liberalization and facilitation of trade and investment, and by engaging in capacity building in its member states.

Thailand was more than ready already to avail of the APEC initiatives. As early as 1961 Thailand had been chosen as a location for UNESCO-Bangkok, later, the Asia-Pacific Bureau for Education, to serve as the Cluster Office from six Mekong countries - Thailand, Myanmar, Lao PDR, and Singapore, and indirectly through UNESCO, Hanoi and Phnom Penh.

Indeed, APEC has already achieved much through "open dialogue, consensus-building and voluntary commitments" (The Economist, 2013, August 24, p. 22).

It should be noted that ASEAN nations are not always listed in the same one standard way. An alternative listing of ASEAN nations includes - Brunei, Cambodia, Indonesia, Laos, Malaysia, Myanmar, Philippines, Singapore, and Thailand - with Vietnam, Papua New Guinea, and Timor-Leste as observer members. 
66 H. S. Bhola

\section{A Nation's Work is Never All Done}

In a recent folder circulated on behalf of Thailand Convention and Exhibition Bureau (TCEB), it was claimed that:

Thailand's economy is diverse, and well-attuned to the dynamics of globalization. Plugged into one of Asia's most dynamic ecosystems, [it is] pivotal to most of the world's business...Asia's markets continue to exert gravitations pull on the rest of the world and South-Asia, with a population of over $630 \mathrm{~m}$ people collectively generate about \$3.6trn in GDP... Confidence in the ten markets of the Association of South East Asian Nation (ASEAN) is rising, and as a collection of markets is rivaling China for its global importance.

It went on to say that:

Thailand scores well in terms of infrastructures: its airports, roads and public transport, and tourist facilities.... A recent national initiative had indeed spent $\$ 80 \mathrm{bn}$ nation-wide improving rail connectivity and other infrastructure. It is one of the most important agricultural industries in the world; also in electronics and digital storage industries; and is among the largest automobile producers in the world.

States do overstate their achievements when reporting on their progress, but Thailand's self-praise is not completely of the mark. Yet, such narrations and valuations of Development in Thailand should not be seen as an invitation for comfortable complacence on the part of political elite, policymakers, planners and administrators. Indeed, the news from the Political world of Thailand is disturbing. The simmering conflict between Madam Yingluck Shinawatra, Prime Minister of Thailand (now Ex-Prime Minister), and her Opponents had swelled into a military coup on June 25, of 2014. We will have to wait and see which way the wind blows. In the economic sector, the urban and rural economies seem to compete rather than complement each other. Quantitative measures of poverty and Gini indicators of income inequality are merely tolerable. In the education sector, again, while quantitative measures for basic primary education may seem good enough, the quality of education actually delivered is another story. Indeed, a nation's work is never all done; and no nation, developing or developed or somewhere in-between, can rest on its laurels.

\section{Planned Interventions for Transformative Change: Dialectics Between The Structural and the Instructional-Informational}

Transformative change: What content, what direction? Not all or any change is good. Change Objective has to stand the test of being Moral and Just; and, of course, be achievable in practice. In our times, Change seeks Inclusion of the excluded based on gender, class or caste or ethnicity. Eradication of Poverty is part of Change Agendas around the world; as also mitigation of global warming in all possible ways, and by consistently pursuing sustainable development. 
Beyond mere commonsense to tested general principles. For handing change within the educational system or to influence change on the national scope, educators will have to go beyond commonsense. They will have to use already tested general principle, in turn, derived from social and behavioral sciences. One such sufficiently tested set of general principles are now embedded in a model offered below:

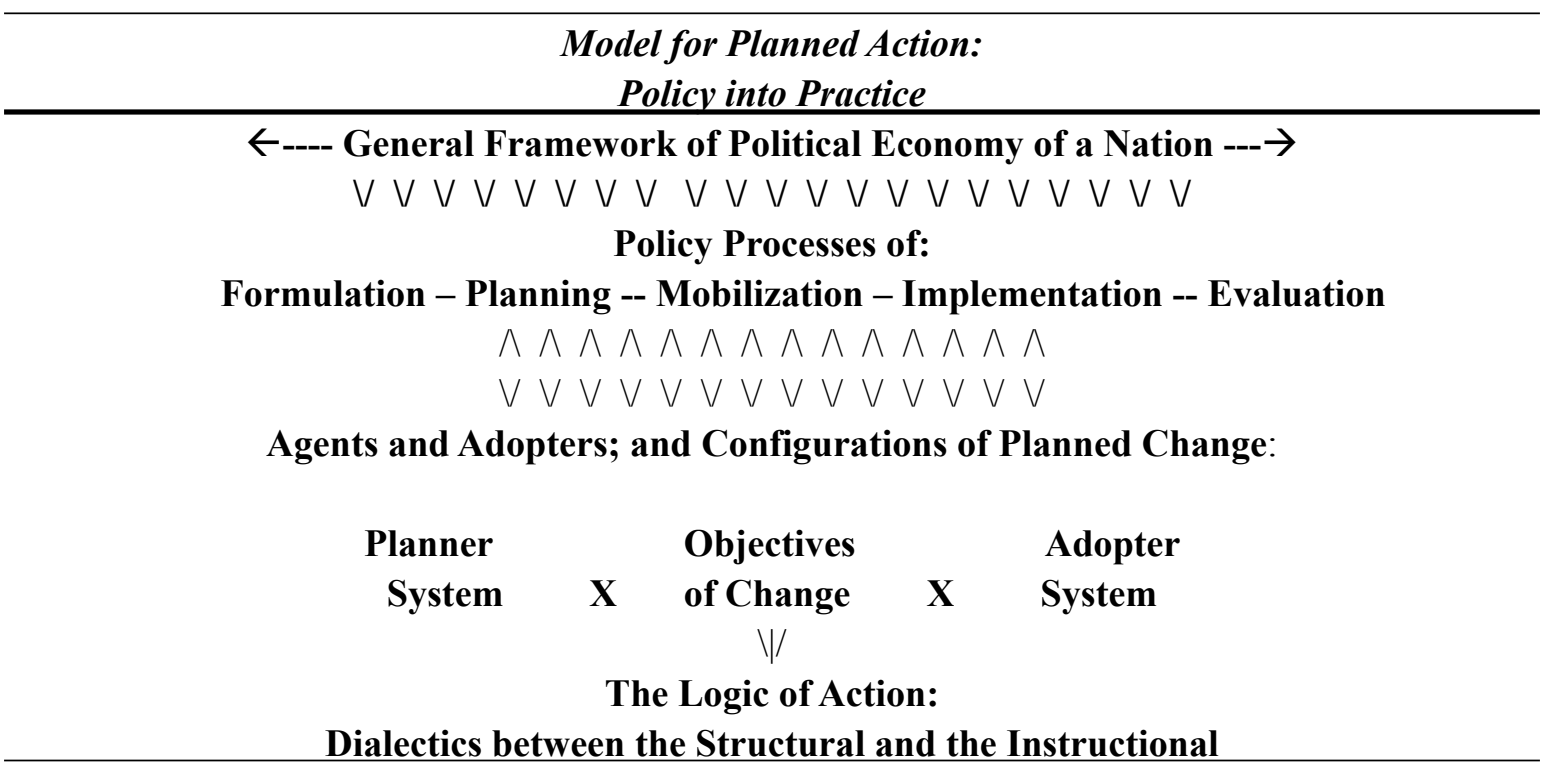

Figure 1. A model for planned action (Bhola, 2013)

The above model of planned change has further implications as outlined below:

Systems thinking and contextualization. The Model, first and foremost suggests that to engage in praxis (i.e., planned social interventions) we should be guided by systems thinking (or holistic thinking) which alone can accommodate Complexities of the real world -- rooted at the same one time in the local and global, reflecting dimensions political, economic, sociological and cultural - and also technological and educational. The Model reminds us also of the need for particular emphasis on the framework of politics and economy of a particular Location, with its specific boundaries. That, in turn, points to the concept of Context; and, in turn, of the need for Contextualization of all processes constituting planned interventions.

The Model also invites attention to the need for developing understandings of policy processes of: formulation, planning, mobilization, implementation, and evaluation -- each of which needs to be well understood for effective use of the Model (Bhola, 2003). This is followed by presentation of the CLER Model, where "C" for Configurations (between and among the social unit such as individual, group, institution, or culture or sub-culture); "L" for Linkages (which may be Formal, or Informal); "E" for Environments (which may be supportive, neutral or inhibitive); and "R" for Resources (which may cognitive-conceptual, 
of influence and goodwill, material, of personnel, institutional, and of time) (Bhola, 198889). Finally, there is the "logic of action" to be generated from the dialectic between the structural and the instructional.

Dialectics between the structural and the instructional. The Logic of Action as conceived in the model comes from the dialectics between the Structural and the Instructional / Informational because we write as educators. Change in the structures of politics and economy is the privilege of politicians. Educators, from the outside, can only educate and inform political actors about the wisdom of their choices and the dynamics and consequences of their choices. Even structures of education are amenable to the will of educators, within limits, set by the all- power political elite.

Yet the role of education and information can indeed be huge and hugely significant and can range from the top levels of governance down to the ground level where field workers may be expected to change levels of usable knowledge and attitudes. At the policy-making level there would be the need to provide appropriate training and to engage in Capacity Building through workshops, seminars, and symposia to meet the needs of policy-makers, planners and administrators. At the field level, it may be training to suit the existent needs of peoples for income generation, and food storage, for family health and childcare.

Not without literacy. Literacy remains the backbone of all education in all its forms and functions. The new technologies of communication can expand, enrich and enhance the role of literacy, but will never supplant it. Literacy as the Chinese say: "Is a portal to all knowledge." It is also known to bestow on the learners a sense of self-worth and the freedom to follow knowledge independently, and encode it to keep and share. No wonder, most adult education programs begin with teaching literacy in the language of common people. In our age of globalization, literacy in the spoken language of people takes us thus far, but no further. Bi-literacy has become a necessity. Some competence in a world language has become a need - in today's world that "world language" happens to be English. Even the proud French and Germans have accepted the role of English as a world language and are publishing their writings in English translation to make those more widely read (Bhola, 2009).

\section{Unpacking the Concept of Education}

Adult literacy helps in promoting more general adult education; women's education; farmers' education; workers education; vocational education for income-generation, as also child-care education; maternal health; HIV/AIDS education; and many others. Adult literacy helps connect with the important educational theme of our times, i.e., lifelong education - the idea being that education never ends, and should indeed be lifelong. By the end of the second millennium, OECD had started talking about lifelong learning, in 
Education for Rural Transformation in Thailand 69

preference to lifelong education -- a dramatic shift, hoping to give Learners responsibility for direction and choice of their own learning, defining own needs for new knowledge, skills and behaviors (UIE, now UIL, 2005; Longworth, 2006)!

\section{References}

Abuom, A. (2010). Where we are. Development and Cooperation: International Journal, $37(12), 17-18$.

Bhola, H. S. (2003). Practical policy analysis for education policy making under globalization. In J. B. G. Tilak (Ed.), Education, society and development: National and international perspectives (pp. 447-460). New Delhi, India: A.P.H. Publishing Corporation for National Institute of Educational Planning and Administration (NIEPA).

Bhola, H. S. (2009). Literacy. In M. J. Bates \& M. N. Maack (Eds.), Encyclopedia of library and information sciences (Vol. 5, 3rd ed., pp. 1-100). New York, NY and London UK: Taylor and Francis.

Bhola, H. S. (2011). A systems theory perspective on education for rural transformation: In the dialectic between global contexts and local conditions. Journal of Educational Planning and Administration, 25(1), 5-19.

Bhola, H. S. (2013). Education for rural transformation (ERT) in India - Dialectics between theory and ideology; the national and the global. Journal of Educational Planning and Administration, 27(3), 257-280.

Bhola, H. S. (1988-89). Knowledge in society. The International Journal of Knowledge Transfer, 1(4), 56-66.

Buasuwan, P. (2012). The role of higher agricultural university in rural transformation: Case study of Kasetsart University, Thailand. Paper presented at the 3rd International ERT Symposium, Baroda (now Vadodara), India.

Chinapah, V., \& Wang, L. (Eds.). (2012). Strategies to achieve balanced inclusive educational development: Equity-quality-internationalization. Stockholm, Sweden: Stockholm University.

Ewing, J. J. (2013). Less hunger, but more health hazards. Development and Cooperation $(D+C), 40(6), 258$.

Food and Agricultural Organization. (2013). Country case studies: Thailand. Decentralized rural development and the role of self help organizations. Retrieved from http://www. fao.org/docrep/004/ac158e/ac158e 08.htm

German Adult Education Association (DVV). (1989). Adult education and development [Special issue]. Proceedings of the World Conference on Education for All, 33.

Government of Thailand. (2007). National human development report: Sufficiency economy and human development. Bangkok, Thailand: Author. 
Interagency Commission (UNDP, UNESCO, UNICEF, World Bank). (1990). World conference on "Education for All: Meeting Basic Learning Needs", 5-9 March 1990, Jomtien, Thailand: Final report. New York, Author.

Jewcharoensakul, S. S. (2012). Successful case "From Farm to Fork": Education promotion for rural development in Thailand. Paper presented at the 3rd International ERT Symposium, Baroda (now Vadodara), India.

Kaboski, J. P., \& Townsend, R. (2005). Policies and impact: An analysis of village-level microfinance institutions. Journal of European Economic Association, 3(1), 1-50.

Lind, A. (1996). Free to speak up: Overall evaluation of the National Literacy Program in Namibia. Windhoek, Namibia: Directorate of Adult Basic Education.

Longworth, N. (2006). Learning cities, learning regions, leaning communities: Lifelong learning and local government. London and New York: Routledge.

McLuhan, M., \& Powers, B. R. (1992). The global village: Transformations in world life and media in the $21^{\text {st }}$ century. London and New York: Oxford University Press.

Myrdal, G. (1968). Asian drama: An inquiry into the poverty of nations. New York, NY: Pantheon.

Phillips, D., \& Ochs, K. (2004). Educational policy borrowing: Historical perspectives. Oxford, U.K.: Symposium Books.

Rumpagaporn, M. W. (2012). Experiences and implementation of information and communication technology (ICT) integration for rural transformation through learning process of small-size schools in Thailand. Paper presented at the 3rd International ERT Symposium, Baroda (now Vadodara), India.

Sarnswang, S. (2012). Sufficiency economy: Some best practices for rural school development in Thailand. Paper presented at the 3rd International ERT Symposium, Baroda (now Vadodara), India.

Singh, M. (Ed.). (2002). Institionalising lifelong learning: Creating conducive environments for adult learning in Asian context. Hamburg: UNESCO Institute for Education (Now UNESCO Institute for Lifelong Learning).

Sunanchai, S. (1989). Fifty years of adult education and non-formal education in Thailand. Adult Education and Development, 33, 7-25.

The Economist. (2013, September 7). Damming the Mekong, fish-friendly? Xayaburi -- A dam takes shape, but fierce opposition continues. The Economist, p. 40.

The Economist. (2013. August 24). The Economist, p. 22.

UNDP. (2011). Thailand country profile: Human development indicators. Retrieved from http://hdrstats.undp.org/en/countries/profiles/THA.html

UNESCO INRULED. (2012). Education and training for rural transformation: Skills, jobs, food and green future to combat poverty. China: Author.

UNESCO. (2000). World Education Forum (Dakar, Senegal, 26-29 April 2000): Final report. Paris, France: UNESCO. 
Education for Rural Transformation in Thailand 71

UNESCO. (2013). Handbook on education policy analysis and programming (Vol. 1 \& 2). Bangkok, Thailand: Author.

United Nations. (2008). Millennium development goals report. New York, NY: Author.

Varavarn, K. (1989). Literacy campaigns and programs in the context of literacy promotion: Lessons learned from Thai experiences. Adult Education and Development, 33, 157165. 